\title{
A basic review of fuzzy logic applications in hydrology and water resources
}

\author{
Shruti Kambalimath ${ }^{1}\left[\right.$ Paresh Chandra Deka $^{1}$
}

Received: 9 April 2018 / Accepted: 2 July 2020 / Published online: 13 July 2020

(c) The Author(s) 2020

\begin{abstract}
In recent years, fuzzy logic has emerged as a powerful technique in the analysis of hydrologic components and decision making in water resources. Problems related to hydrology often deal with imprecision and vagueness, which can be very well handled by fuzzy logic-based models. This paper reviews a variety of applications of fuzzy logic in the domain of hydrology and water resources in brief. So far in the literature, fuzzy logic-based hybrid models have been significantly applied in hydrologic studies. Furthermore, in this paper, the literature is reviewed on the basis of applications using pure fuzzy logic models and applications using hybrid-fuzzy modeling approach. This review suggests that hybrid-fuzzy modeling approach works well in many applications of hydrology when compared with pure fuzzy logic modeling.
\end{abstract}

Keywords Fuzzy logic $\cdot$ Hydrology $\cdot$ Water resources $\cdot$ Hybrid-fuzzy modeling

\section{Introduction}

Fuzzy logic is a well-known soft computing tool which develops the workable algorithms by embedding structured human knowledge. It is a logical system that presents a model designed for human interpretation modes that are inexact rather than precise. The fuzzy logic system can be applied to design intelligent systems on the basis of information expressed in human language (Bai et al. 2006). Fuzzy logic is one of the forms of artificial intelligence; however, its history and uses are newer than artificial intelligence based expert systems. Fuzzy logic deals with problems that have imprecision, vagueness, approximations, uncertainty or qualitative mess or partial truth.

Fuzzy logic was introduced by Professor L. A. Zadeh, University of California at Berkeley, in the year 1965 (Zadeh 1965; Bai et al. 2006) through his paper 'Fuzzy sets.' His work was not recognized until Dr. E. H. Mamdani, Professor at London University, practically applied the concept of

Shruti Kambalimath

shruti.kambalimath38@gmail.com

Paresh Chandra Deka

dekanitk@gmail.com

1 Department of Applied Mechanics and Hydraulics, National Institute of Technology Karnataka, Surathkal, Mangaluru 575025, India fuzzy logic to control an automatic steam engine in the year 1974 (Mamdani and Assilion 1974; Bai et al. 2006).

Since the beginning of applications of fuzzy logic in the domain of hydrology (Bogardi et al. 1983, 2004) a great sum of investigations have been undertaken, and presently, fuzzy logic has turned into a useful approach in water resources assessment and hydrologic analysis. Hydrology is often vulnerable to uncertainties caused due to lack of data, nature causes (e.g., climate) and imprecision's in modeling. System limitations and initial conditions as well bring in uncertainty. In addition, potential pressure on the system cannot be clearly identified in many hydrologic studies. Fuzzy logic allows us to consider the handling of all such vagueness (or ambiguity) in hydrology (Bogardi et al. 2004).

In order to employ a systems approach, it is necessary to change the fundamental understanding of physical reality under consideration (Simonovic 2008). New researchers have focused on the application of fuzzy logic-based techniques for modeling vagueness within the water resource systems. So far in the literature, many research contributions have been made for dealing with the vagueness in water resources systems which include fuzziness, bias, ambiguity and deficiency of ample data (Mujumdar and Ghosh 2008).

'Fuzzy rule-based modeling' is an extension of the concept of fuzzy logic. The key difference in fuzzy logic and fuzzy rule-based modeling is that the former is used for systems with feedback and the latter is used for systems with no

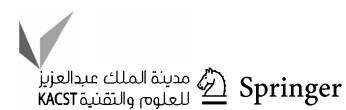


feedback process (Sugeno and Yasukawa 1993; Wang and Mendel 1992; Decampos and Moral 1993; Bogardi et al. 2004). The idea of application of FL in the modeling of the hydrologic systems is comparatively fresh and innovative (Bardossy et al. 1995).

Some of the areas of fuzzy logic application in hydrology include: fuzzy-based regression (Bardossy et al. 1990; Bardossy et al. 1991; Ozelkan and Duckstein 2000; Bogardi et al. 2004), hydrologic forecasting (Kojiri 1988; Bogardi et al. 2004), hydrologic modeling (Hundecha et al. 2001; Bogardi et al. 2004), regional water resources management (Bogardi et al. 1982; Nachtnebel et al. 1986; Bardossy et al. 1989, Bogardi et al. 2004), reservoir operation planning (Simonovic 1992; Shrestha et al. 1996; Teegavarapu and Simonovic 1999; Bogardi et al. 2004), water resources risk assessment (Feng and Luo 2011) and so on.

To increase the accuracy of fuzzy systems, various studies have been undertaken for years and the major inference is that fuzzy hybrid modeling can efficiently increase the accuracy of fuzzy system modeling. New advances have been taken place in the fields of adaptive fuzzy operators (Terzi et al. 2006), genetic fuzzy systems modeling (Guan and Aral 2005; Han et al. 2012) and wavelet-fuzzy modeling (Partal and Kisi 2007), which will be discussed in further sections of this article.

From the early application of fuzzy logic to hydrology (Bogardi et al. 1983), a large amount of research has been pursued and, at present, fuzzy logic has become a practical tool in hydrologic analysis and water resources decision making. In this paper, the main areas of applications in hydrology and water resources are highlighted.

\section{General methodology (work-flow of fuzzy logic systems)}

In order to apply FL technique to a practical application problem, the following steps are to be followed (Bai et al. 2006):

1. Fuzzification - this step involves the conversion of crisp data or classical data into fuzzy set data or the membership functions (MFs)

2. Fuzzy inference process - this process consists of combining MFs along with the fuzzy control rules to obtain the fuzzy output

3. Defuzzification - this process is the reverse process of fuzzification. It involves the conversion of the fuzzy output into crisp output along with associated rules (as shown in Fig. 1).

Machines are capable of processing crisp data such as the binary system (' 0 ' or ' 1 ') and can be facilitated to handle uncertain linguistic data such as 'high' and 'low' if the



Fig. 1 Workflow of a fuzzy logic system (Bhattacharjee et al. 2018)

crisp input and output are converted to linguistic variables along with the fuzzy components. Moreover, both the crisp input and the crisp output have to be converted to fuzzy data. All of these conversions are carried out by the first step-fuzzification.

The second step is the fuzzy inference process (FIS) where membership functions (MFs) are combined with the control rules in order to derive the fuzzy control output, and the outputs are arranged into a table format called as the 'lookup table.' In FIS, the important is the fuzzy control rules. Those rules are as similar as that of human being's inference and intuition to the course of action. Various methods such as mean of maximum (MOM) or center of gravity (COG) are been used to work out the related control output, and each one of the control output must be arranged into a table format called lookup table.

For a real-life application, a fuzzy control output must be chosen from the lookup table developed in the previous step based on the present input. Further, that fuzzy control output must be transformed from the linguistic variable form to the sharp or crisp variable and perform the control operator. The process is known as defuzzification or step 3.

Real-life applications are usually associated with input variables having more than one dimension. In such cases, one needs to develop the membership functions for each dimensional variable separately and the similar operation needs to be carried out if the system consists of multiple output variables.

To summarize, the fuzzy system modeling is a chain of crisp-fuzzy-crisp transformation used to derive results for an actual working system. The initial input and the final output must necessarily be crisp variables; however, the transitional stage is a fuzzy inference process, where the linguistic 
variables are used to derive the outputs. The motive why there is need to transform a sharp or crisp variable to a fuzzy variable is that, from the principle of fuzzy system process or a human's inference or intuition, no absolutely crisp variable exists in our factual world.

\section{Applications in the field of surface water hydrology}

Fuzzy rule-based systems were successfully applied for drought evaluation (Pesti et al. 1996), forecasting of rainfall patterns (Abebe et al. 2000), investigation of uncertainty in modeling groundwater flow (Abebe et al. 2000), water levels control in polder areas (Lobbrecht and Solomatine 1999), modeling the dynamics of rainfall streamflow (Vernieuwe et al. 2005) and so on. Some selective applications are listed as follows:

\section{Applications in evaporation and evapotranspiration}

Fuzzy models were developed in literature for daily pan evaporation assessment from observed meteorological records. Penman equation, which is most widely used, is used to compare with the fuzzy model results. Theory of FL was successfully applied for estimating monthly pan evaporation with meteorological data as input (Atiaa and Abdul-qadir 2012). This study concluded that the approach of FL is adequate and intelligent for evaporation modeling. Fuzzy models were also developed for estimating of daily pan evaporation, and outcomes were compared with Penman method (Keskin et al. 2004). The fuzzy model proved a better agreement with observed data than the Penman method. Similarly, evapotranspiration (ET) was estimated and predicted using fuzzy inference system (FIS) by Patel and Balve (2016), and the results were compared with the FAO-56 Penman-Monteith method. FIS showed a high efficiency in predicting and estimating ET values.

\section{Rainfall-runoff (R-R) modeling}

Huge cost and labor use experienced in past for developing a water resource project request a lot of consideration in contriving exact $\mathrm{R}-\mathrm{R}$ models for its fruitful execution. These models are reliant on the physiographic, climatic and biotic qualities of the watershed. These elements now and again actuate either a direct, nonlinear or profoundly complex behavior among the precipitation and runoff parameters. The unstructured idea of $\mathrm{R}-\mathrm{R}$ relations has occupied the consideration of specialists toward soft computing techniques (Chandwani et al. 2015).

Hundecha et al. (2001) developed a fuzzy rule-based routine in order to simulate the generation of runoff using precipitation data. A fuzzy conceptual framework for rainfall-runoff modeling was proposed to deal with uncertainties of every element of R-R modeling (Özelkan and Duckstein 2001). The study showed that FL framework facilitates the decision maker to realize model sensitivity and uncertainty resulting from elements of R-R modeling. Further, a fuzzy rule-based system (FRBS) was developed using Takagi-Sugeno-Kang approach to forecast the definite discharge at the outlet of the catchment in which soil moisture was used as the input variable (Casper et al. 2007).

\section{Floods and droughts}

Flood disasters are among the world's most recurrent and destructive kinds of catastrophes (World Disaster Report 1998; Jiang et al. 2009). Flood risk, disasters and hazards are the products of an interface between social and environmental processes (Parker 2000; Jiang et al. 2009). Several researchers used the fuzzy numerical technique to investigate flood forecasting and risk evaluation (Jiang et al. 2008; Mao and Wang 2002; Nayak et al. 2005; Jiang et al. 2009).

Flood disaster risk was assessed by Jiang et al. (2009) using three fuzzy-based methods such as fuzzy similarity method (FSM), simple fuzzy classification (SFC) and fuzzy comprehensive assessment (FCA). It was found that the FCA method is more reliable for the study area than the other two techniques. An attempt was made to enhance the real-time flood forecasting using a modified Takagi-Sugeno (T-S) FIS (Lohani et al. 2014). The model forecast was reasonably accurate with sufficient lead time. A flood forecasting model based on Mamdani FIS was developed by Perera and Lahat (2015) in order to assess the potential of fuzzy logic in real-time flood forecasting. A fuzzy logic-based method and geographical information system (GIS) were combined to analyze mass evacuation decision support system (Jia et al. 2016). It was helpful in illustrating the importance of evacuation maps in crisis management.

Fuzzy models were also used as updating technique in order to improve flood forecasting models ( $\mathrm{Yu}$ and Chen 2005). A study on estimating the potential impacts of climate change on droughts was carried out by Pesti et al. (1996). In this study, fuzzy rules were applied to forecast droughts with the help of atmospheric circulation patterns.

\section{Reservoir operation (RO)}

Fuzzy rule-based models were successfully developed by the researchers in order to derive rules for operating a multipurpose reservoir (Shrestha et al. 1996) and single purpose reservoir (Panigrahi and Mujumdar 2000). Further, the complexity of fuzzy modeling for RO was reduced by reducing the fuzzy rules (Sivapragasam et al. 2008) and the results were highly encouraging the purpose of the study. 
Dubrovin et al. (2002) applied the fuzzy model for realtime reservoir operation. A new methodology for fuzzy inference was developed, called as total fuzzy similarity. The study illustrated the strong mathematical background of the FIS makes the fuzzy reasoning to have a solid foundation.

\section{Deriving stage-discharge (S-D) relationship and prediction of sediment concentrations}

A fuzzy rule-based model was developed for deriving S-Dsediment concentration relationship, and the result was compared with conventional sediment rating curves and neural networks (Lohani et al. 2007). The fuzzy model showed better results and potentiality for its application in prediction of sediment concentration. Streamflow prediction was done using two FISs (Ozger 2009), and the results showed that Mamdani type of fuzzy inference modeling performs better than that of Takagi-Sugeno fuzzy inference systems for river discharge prediction.

Fuzzy models were developed as a superior alternative to traditional sediment rating curves for determining the suspended sediment concentration on a daily basis for a given river section (Kisi 2004). The study showed that fuzzy models prove their superiority in comparison with the rating curve models for the same input data. Further, Kisi et al. (2006) used the FL approach to carry out river suspended sediment modeling. They concluded that the proposed fuzzy model was site-specific and failed to simulate the effects of hysteresis.

\section{Water quality modeling and water treatment}

A fuzzy optimization model was developed for river water quality management on a seasonal basis (Mujumdar and Sasikumar 2002). The model successfully gave solutions for removal of pollutants on seasonal fraction basis. Icaga (2007) developed an index model for surface water quality classification based on the fuzzy logic concept. The study demonstrated the feasibility and practical application of the index. A two-stage fuzzy set theory was applied to river quality evaluation (Liou et al. 2003; Ip et al. 2009). A FIS was used to assess the river water quality, and the results were compared with a widely used method like water quality index (WQI) (Abdullah et al. 2008). The results clearly indicated that FIS can be successfully used to harmonize the discrepancies and the internal complexities of river water quality assessment.

Surface water quality was assessed by developing an indicator based on fuzzy logic. The results were compared with conventional WQI, in which fuzzy indicator provided better results (Oroji et al. 2017). Chang et al. (2001) studied the identification of river water quality by using three fuzzy synthetic evaluation techniques, and the outputs were compared with a conventional procedure like WQI.

Superior capabilities of the fuzzy logic concept in handling the nonlinearity, complexity and uncertainty of systems were illustrated by Bai et al. (2009) in their study of WQI based on fuzzy logic. A new WQI based on fuzzy (FWQI) was developed, and the outcomes were compared with two other indices (González et al. 2011). FWQI proved to be a potential index for a decision maker in water management. Fuzzy-based models were successfully developed for forecasting WQI in the municipal water distribution system (Patki et al. 2013), and the results of the fuzzy model were compared with adaptive neuro-fuzzy (ANFIS) models. The study revealed that fuzzy models outperformed as that of ANFIS models. Sedeño-Díaz and López-López (2016) studied reservoir water quality using a fuzzy logic model.

Surendra and Deka (2014) used Mamdani FIS for predicting water consumption using different climatic variables. Performance indicators showed the capability of fuzzy logic in predicting the water consumption in a municipal water distribution system. A novel approach based on fuzzy logic was developed for water quality assessment, especially for human drinking purposes (Gharibi et al. 2012). Fuzzy controller systems were designed and implemented by the researchers in regulating an aeration system in a water treatment plant (Fiter et al. 2005). The results illustrated that more than $10 \%$ energy savings can be achieved using fuzzy aeration control while still keeping the removal levels good. A fuzzy multi-criteria decision-making method was developed to select the optimal strategy for the rural water supply, and the results were quite promising (Minatour et al. 2015).

\section{Downscaling of climate variables}

The art of applying fuzzy rule-based techniques for downscaling of climate variables can be seen since two decades. Bardossy et al. (1995) applied the fuzzy-based method to classify the daily atmospheric circulation patterns (CPs). They stated that the fuzzy rule-based approach has high potential applications in the classification of general circulation models (GCMs). Clustering and classification of large-scale atmospheric CPs using multi-objective fuzzy technique were done by Özelkan et al. (1998). An automated objective classification of CPs for precipitation and temperature downscaling on daily basis was carried out based on optimized fuzzy rules (Bárdossy et al. 2002). The method produced physically realistic CPs. Fuzzy-based classification for downscaling was compared with two methods, analog method and statistical downscaling model (Teutschbein et al. 2011). The study demonstrated that the suitability of downscaling technique was highly variable with river basin under consideration. 


\section{Applications in the field of groundwater hydrology}

Some of the important fields of fuzzy logic applications in the field of groundwater hydrology are as listed in Table 1.

\section{Applications of hybrid-fuzzy models}

Some of the selective applications of fuzzy hybrid models in water resources are listed in Table 2.

\section{Results and discussions on the literature reviewed so far}

As mentioned before, fuzzy logic can very well handle the uncertainty or vagueness associated with hydrologic problems. Hence in many of the literature, fuzzy-based models have shown better performance in comparison with the conventional methods. In modeling evaporation, fuzzy modeling proved a better agreement with observed data when compared with the widely used Penman method (Atiaa and Abdul-qadir 2012; Keskin et al. 2004; Patel and Balve 2016).

Özelkan and Duckstein (2001) showed that FL framework facilitates the decision maker to realize model sensitivity and uncertainty resulting from elements of $\mathrm{R}-\mathrm{R}$ modeling. In flood modeling, fuzzy models were well verified for the performance and different fuzzy models like fuzzy comprehensive assessment, simple fuzzy classification and fuzzy similarity method were compared with each other (Jiang et al. 2009).

Streamflow prediction was carried out using two fuzzy inference systems, namely Mamdani type and Takagi-Sugeno type inference systems, where the former showed better performance (Ozger 2009). Fuzzy models were proved to be outperforming in both stream water quality modeling (Chang et al. 2001) and municipal water distribution (Patki et al. 2013).

Fuzzy models were developed in different fields of groundwater hydrology like infiltration modeling, regional groundwater management, groundwater remediation, aquifer studies and groundwater pollution assessment, where fuzzy models have shown better performance.

Among the various hybrid-fuzzy models developed so far, fuzzy neural comes out to be the most widely used model in various hydrologic studies. ANFIS showed its better performing capabilities in fields like evaporation (Terzi et al. 2006); fuzzy neural network model produced good results in deriving stage-discharge relationship when compared to conventional curve fitting method (Deka and Chandramouli 2003).

Different combinations of hybrid-fuzzy modeling, like wavelet-fuzzy, wavelet-ANFIS, fuzzy-SVM, fuzzy-genetic algorithms and so on, were well experimented (as shown in Table 2), and the results show the potentiality of fuzzy systems in modeling the hydrologic components (Figs. 2, 3).

\section{Merits and demerits of fuzzy logic}

\section{Merits of fuzzy logic}

Fuzzy logic explains schemes in expressions of a mixture of numerics and linguistics (symbolic). It has compensation over pure numerical (mathematical) methods or pure symbolic methods because frequently system information is accessible in such a mixture.

Problems for which a specific mathematically fixed account is missing or is only obtainable for very limited conditions can repeatedly be undertaken by fuzzy logic, given a fuzzy model is in attendance. Fuzzy logic at times uses only estimated data, so easy sensors can be employed. The algorithms can be explained by minute data, so minute memory is necessary.

The algorithms are frequently quite comprehensible. Fuzzy algorithms are frequently vigorous, in the logic that they are not very responsive to altering environments and mistaken or away from rules. The logic process is habitually simple, assessed to computationally exact systems, so computing influence is reserved. This is a fascinating feature, mainly in real-time systems. Fuzzy methods frequently have a shorter growth time than conventional methods.

\section{Demerits of fuzzy logic}

Fuzzy logic sums up to the function estimation in the case of crisp-input/crisp-output systems. The meaning is that in numerous cases, using fuzzy logic is just a dissimilar way of performing exclamation. In domains that have excellent mathematical imagery and solutions, the use of fuzzy logic most frequently may be rational when calculating power (i.e., time and memory) limits are too rigorous for an absolute mathematical realization.

Cautious examination of contrast examples, 'proving' the advantage of fuzzy logic frequently shows that they are in contrast the fuzzy technique with a very straightforward, non-optimized traditional method. Proof of individuality of fuzzy systems is not easy or unworkable in many cases because of the absence of mathematical explanations; particularly in the areas of stability of control systems which is a vital research point. 
Table 1 Some of the literature showing applications of fuzzy logic in the field of groundwater hydrology

\begin{tabular}{lll}
\hline Sl. no. & References & Applications \\
\hline 1 & Bardossy and Disse (1993) & Infiltration modeling
\end{tabular}

\section{Groundwater quality assessment}

Regional aquifer management

Groundwater remediation

\section{Groundwater pollution risk assessment}

Groundwater quality index
Recharge wells site selection in urban area
Data used/models developed/results obtained

Two fuzzy-based models were developed based on different training sets and rules. Results were in good agreement with observed infiltration values

Designed a fuzzy logic-based approach for assessing potential infiltration areas in watersheds with a low gradient and mapping of the same. Remote sensing data were used for the purpose

Fuzzy set analysis for combining $\mathrm{N}$ environmental objectives into one single fuzzy membership function. Application of the model to the nonlinear case is also included in the study

Two fuzzy optimization models were developed for the optimal design of groundwater remediation systems. Results were compared with the results of the probabilistic analysis. Both models provided reliable and flexible strategies and increase the effectiveness of the groundwater remediation system under uncertainty

Developed a fuzzy-based tool called fuzzy spatial reliability analysis (FUZZY-SRA) for analysis and modelization of vulnerability of aquifer. FUZZY-SRA functioned as a tool inside GIS software

FL was used to calculate the water pollution index and the values indicated high to moderate levels of groundwater pollution

The fuzzy set theory was applied for decision making in groundwater quality assessment for drinking purposes. Results showed the high capability of FL to assess groundwater quality

Fuzzy-based model was developed for assessment of groundwater vulnerability and risk of aquifer contamination. The model involved sensitivity analysis to deal with the uncertainty associated with input data and the model itself

The suitability of groundwater for drinking purpose was checked by estimating the water quality index using fuzzy aggregation approach. The outputs were compared with widely used weighted arithmetic mean aggregation

A coactive neuro-fuzzy inference system (CANFIS) method was applied to simulate groundwater quality and the results were mapped using GIS software. The results showed high efficiency of CANFIS and GIS models together

Hydraulic conditions such as hydraulic conductivity, specific recharge, distance to production water wells and depth of groundwater table were considered as input layers to Mamdani fuzzy inference system. Site selection was done based on 'High' priorities of number of pixels for the above-mentioned input layers 
Table 1 (continued)

\begin{tabular}{lll}
\hline Sl. no. & References & Applications \\
\hline 12 & Nadiri et al. (2019) & Modeling groundwater level variations
\end{tabular}

Human health risk assessment of fluoride-rich groundwater Assessment of over-exploitation of ground-
water

dentifying potential zones of groundwater recharge

Modeling of groundwater level

Impact of drought on quantity of groundwater
Data used/models developed/results obtained

Three fuzzy logic models, namely Sugeno, Mamdani and Larsen models, were used to model time series of groundwater levels. The models were developed based on management scenario. This study revealed that water table variations are more effected by aquifer water use than climatic variation

Groundwater levels were analyzed using spatial analysis tools like geostatistical tools. Fuzzy logic was applied to improve the performance of ordinary kriging method. This study showed that fuzzy logic approach leads to Gaussian variogram model which increased the performance significantly

This study compared the conventional hazard index (HI) with fuzzy hazard index (FHI) to assess the effect of fluoride on human health. They found that fuzzy method was superior than the conventional method

Fuzzy logic was integrated with a GIS environment to identify the potential zones of groundwater recharge. Fuzzy membership values were assigned to different thematic layers

Aquifer level fluctuations were studied by using two types of variogram functions and compared with space-time ordinary kriging. Both the functions performed better than ordinary kriging

Groundwater exploitation was assessed using different methods, namely multi-criteria decision analysis (MCDA), analytical hierarchy process (AHP), fuzzy logic and ensemble method in a GIS environment. All the methods performed well

This study used fuzzy logic and ArcGIS to assess the impact of drought on quantity of groundwater, They found that groundwater levels depend on rainfall and other water inputs like irrigation networks

\section{Conclusion}

Fuzzy-based modeling approach is increasingly been applied in most of the fields of hydrology and water resources as it can take the uncertainties into consideration. It can also be applied effectively in cases like missing data in longterm time series, unavailability of data, prediction of time series, etc. Due to its capacity to consider the uncertainty and vagueness, it works efficiently in real-time forecasting applications. Literature shows a wide range of applicability of fuzzy logic in surface water hydrology, groundwater hydrology, irrigation technology, etc. Literature studies also show that fuzzy models are often combined with other models and the hybrid-fuzzy modeling is found to be more efficient than pure fuzzy modeling in many of the applications. In comparison with models like ANN, SVM, fuzzy models show moderate accuracy but prove a better performance when combined with other models.

\section{Scope for future work}

- Investigation of a best suitable hybrid-fuzzy model for application in hydrologic studies.

- Among the hybrid-fuzzy models, ANFIS is most widely used and accepted technique so far. It can be used for assessing the performance of hybrid-fuzzy models for the same study.

- Fuzzy logic has proven its performance in prediction studies. Hence, its predictive power can be used effectively in hydrologic time series forecasting. 


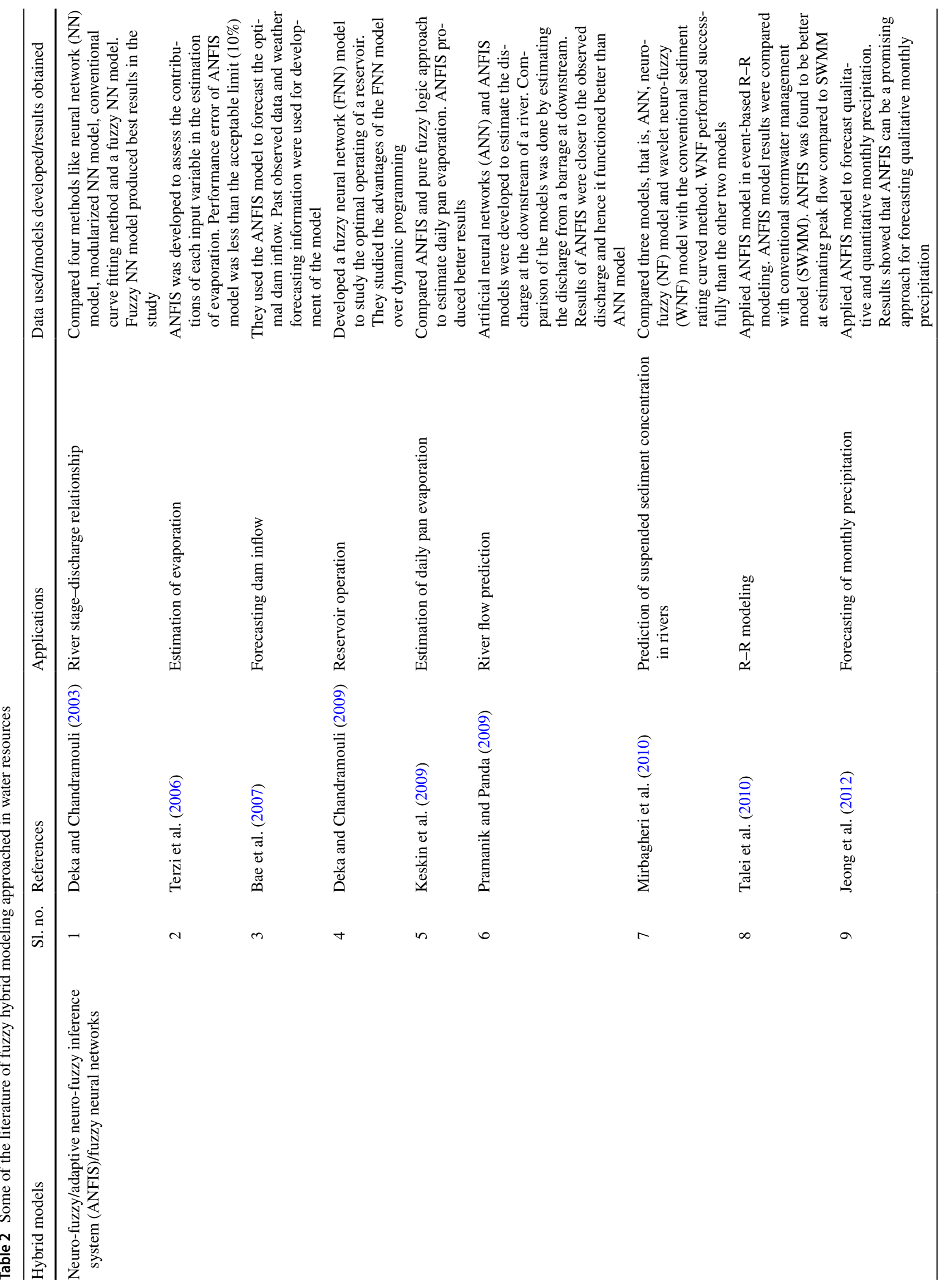




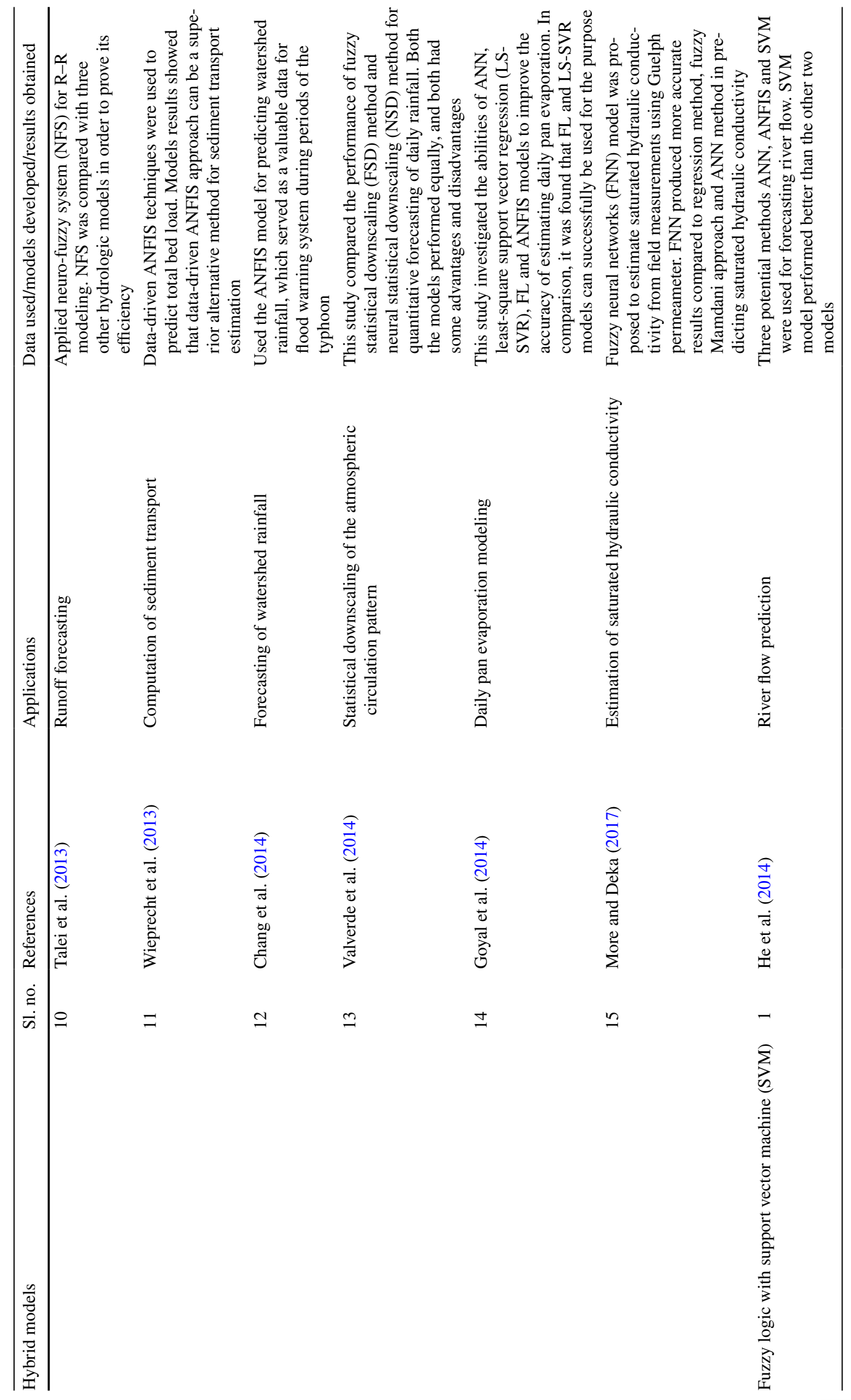




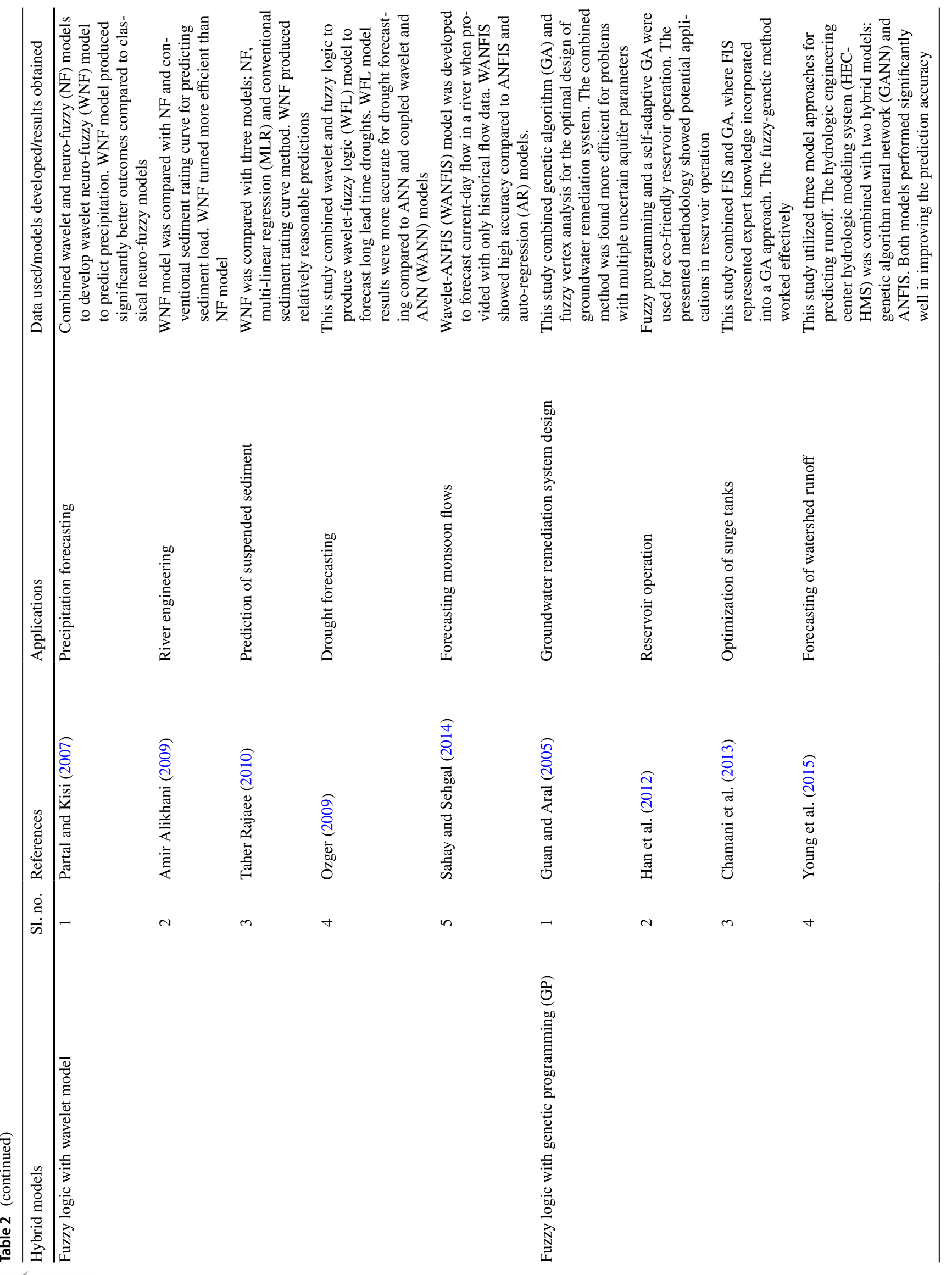




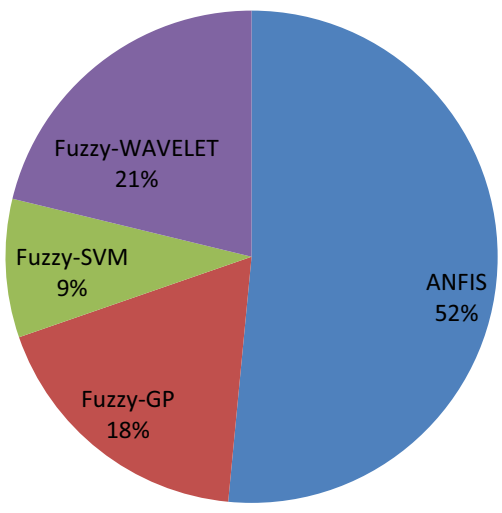

Fig. 2 Pie chart representation showing the application of hybridfuzzy models so far

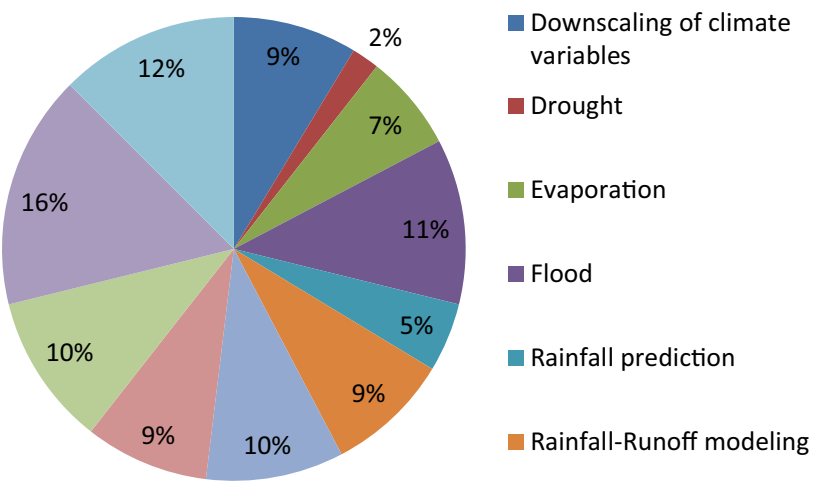

Fig. 3 Pie chart showing representative proportions of various applications of FL in hydrology and water resources

- The performance evaluation of pure fuzzy modeling and hybrid-fuzzy modeling can be an important research in many hydrologic applications.

- Fuzzy logic-based models can efficiently deal with problems where data are scanty or limited.

Funding No funding applicable.

\section{Compliance with ethical standards}

Conflict of interest The authors declare that they have no conflict of interest.

Open Access This article is licensed under a Creative Commons Attribution 4.0 International License, which permits use, sharing, adaptation, distribution and reproduction in any medium or format, as long as you give appropriate credit to the original author(s) and the source, provide a link to the Creative Commons licence, and indicate if changes were made. The images or other third party material in this article are included in the article's Creative Commons licence, unless indicated otherwise in a credit line to the material. If material is not included in the article's Creative Commons licence and your intended use is not permitted by statutory regulation or exceeds the permitted use, you will need to obtain permission directly from the copyright holder. To view a copy of this licence, visit http://creativecommons.org/licenses/by/4.0/.

\section{References}

Abdullah M, Waseem Sadia, Raman Bai V, Ijaz-ul-Mohsin (2008) Development of a new water quality model using the fuzzy logic system for Malaysia. Open Environ Sci 2:101-106

Abebe AJ, Guinot V, Solomatine DP (2000) Fuzzy alpha-cut vs. Monte Carlo techniques in assessing uncertainty in model parameters. In: Proceedings of 4th international conference on hydroinformatics, Cedar Rapids

Alikhani A (2009) Combination of neuro-fuzzy and wavelet model usage in river engineering. Int J Energy Environ 3:122-134

Aouragh MH, Essahlaoui A, Ouali AE, Hmaidi AE, Kamel S (2016) Groundwater potential of Middle Atlas plateaus, Morocco, using fuzzy logic approach, GIS and remote sensing. Geomat Nat Hazards Risk 8(2):194-206

Atiaa AM, Abdul-qadir AM (2012) Using fuzzy logic for estimating monthly pan evaporation from meteorological data in Emara/ South of Iraq. Baghdad Sci J 9(1):133-140

Bae DH, Jeong DM, Kim G (2007) Monthly dam inflow forecasts using weather forecasting information and neuro-fuzzy technique. Hydrol Sci J 52:99-113

Bai Y, Zhuang H, Wang D (2006) Fundamentals of fuzzy logic control-fuzzy sets, fuzzy rules, and defuzzification. In: Advanced fuzzy logic technologies in industrial applications. XXV, $334 \mathrm{pp}$, ISBN: 978-1-84628-468-7

Bai RV, Bouwmeester R, Mohan S (2009) Fuzzy logic water quality index and the importance of water quality parameters. Air Soil Water Res 2:51-59

Bardossy A, Disse M (1993) Fuzzy rule-based models for infiltration. Water Resour Res 29(2):373-382

Bardossy A, Bogardi I, Duckstein L, Nachtnebel P (1989) Fuzzy decision-making to resolve regional conflicts between industry and the environment. In: Evans CW, Karwowski W, Wilhelm PM (eds) Fuzzy methodologies for industrial and systems engineering, chapter 3. Elsevier, Amsterdam

Bardossy A, Bogardi I, Duckstein L (1990) Fuzzy regression in hydrology. Water Resour Res 25(7):1497-1508

Bardossy A, Hagaman R, Duckstein L, Bogardi I (1991) Fuzzy least squares regression: theory and application. In: Fedrizzi M, Kacprzyk J (eds) Fuzzy regression models. Omnitech Press, Warsaw, pp 66-86

Bardossy A, Duckstein L, Bogardi I (1995) Fuzzy rule-based classification of atmospheric circulation patterns. Int J Climatol 15:1087-1097

Bárdossy A, Stehlík J, Caspary HJ (2002) Automated objective classification of daily circulation patterns for precipitation and temperature downscaling based on optimized fuzzy rules. Clim Res 23:11-22

Bhattacharjee D, Kim W, Chattopadhyay A, Waser R, Rana V (2018) Multi-valued and fuzzy logic realization using TaOx memristive devices. Sci Rep. https://doi.org/10.1038/s41598-017-18329-3

Bogardi I, Duckstein L, Szidarovszky F (1982) Bayesian analysis of underground flooding. Water Resour Res 18(4):1110-1116

Bogardi I, Duckstein L, Bardossy A (1983) Regional management of an aquifer under fuzzy environmental objectives. Water Resour Res 19(6):1394-1402

Bogardi I, Bardossy A, Duckstein L, Pongracz R (2004) Chapter 6 fuzzy logic in hydrology and water resources, fuzzy logic in geology. Elsevier Science, Amsterdam, pp 153-190 
Borna R, Hassan F (2020) The impact of the phenomenon of drought on groundwater quantity using fuzzy model (case study: plain Gotvand-Aghili). Wetl Ecobiol 12(1):29-46

Caniani D, Lioi DS, Mancini IM, Masi S, Sdao F (2011) Fuzzy logic model development for groundwater pollution risk assessment. Eur Water Publ 35:13-22

Casper M, Gemmar P, Gronz O, Johst M, Stüber M (2007) Fuzzy logicbased rainfall-runoff modeling using soil moisture measurements to represent system state. Hydrol Sci J 52:478-490

Chamani MR, Pourshahabi S, Sheikholeslam F (2013) Fuzzy genetic algorithm approach for optimization of surge tanks. Sci Iran 20:278-285

Chandwani V, Vyas SK, Agrawal V, Sharma G (2015) Soft computing approach for rainfall-runoff modelling: a review. In: Aquat. Procedia, international conference on water resources, coastal and ocean engineering (Icwrcoe 2015), pp 1054-1061

Chang N, Bin Chen HW, Ning SK (2001) Identification of river water quality using the fuzzy synthetic evaluation approach. J Environ Manage 63:293-305

Chang FJ, Chiang Yen-Ming, Tsai Meng-Jung, Shieh Ming-Chang, Hsu Kuo-Lin, Sorooshian Soroosh (2014) Watershed rainfall forecasting using neuro-fuzzy networks with the assimilation of multi-sensor information. J Hydrol 508:374-384

Das B, Pal SC (2020) Assessment of groundwater vulnerability to overexploitation using MCDA, AHP, fuzzy logic and novel ensemble models: a case study of Goghat-I and II blocks of West Bengal, India. Environ Earth Sci 79:104

DeCampos LM, Moral S (1993) Learning rules for a fuzzy inference model. Fuzzy Sets Syst 59(3):247-257

Deka P, Chandramouli V (2003) A fuzzy neural network model for deriving the river stage-discharge relationship. Hydrol Sci J 48:197-209

Deka PC, Chandramouli V (2009) Fuzzy neural network modeling of reservoir operation. J Water Resour Plan Manag 135:5-12

Di Martino F, Sessa S, Loia V (2005) A fuzzy-based tool for modelization and analysis of the vulnerability of aquifers: a case study. Int J Approx Reason 38:99-111

Dubrovin T, Jolma A, Turunen E (2002) Fuzzy model for real-time reservoir operation. J Water Resour Plan Manag 128:66-73

Feng LH, Luo GY (2011) Application of possibility-probability distribution in assessing water resource risk in Yiwu city. Water Resour 38:409-416

Fiter M, Güell D, Comas J, Colprim J, Poch M, Rodríguez-Roda I (2005) Energy saving in a wastewater treatment process: an application of fuzzy logic control. Environ Technol 26:1263-1270

Gharibi H, Mahvi AH, Nabizadeh R, Arabalibeik H, Yunesian M, Sowlat MH (2012) A novel approach in water quality assessment based on fuzzy logic. J Environ Manag 112:87-95

Ghazavi R, Babaei S, Erfanian M (2018) Recharge wells site selection for artificial groundwater recharge in an urban area using fuzzy logic technique. Water Resour Manag J. https://doi.org/10.1007/ s11269-018-2020-7

Gholami V, Khaleghi MR, Man Sebghati (2016) Method of groundwater quality assessment based on fuzzy network-CANFIS and geographic information system (GIS). Appl Water Sci 7:3633-3647

González JDH, Carvajal LFS, Toro FMB (2011) Water quality index based on fuzzy logic applied to the Aburra river basin in the jurisdiction of the metropolitan area. Dyna 171:50-58

Gorai AK, Hasni SA, Iqbal J (2016) Prediction of groundwater quality index to assess suitability for drinking purposes using fuzzy rule-based approach. Appl Water Sci 6:393-405

Goyal MK, Bharti B, Quilty J, Adamowski J, Pandey A (2014) Modeling of daily pan evaporation in subtropical climates using ANN, LS-SVR, fuzzy logic, and ANFIS. Expert Syst Appl 41:5267-5276
Guan J, Aral MM (2004) Optimal design of groundwater remediation systems using fuzzy set theory. Water Resour Res 40:1-20

Guan J, Aral M (2005) Remediation system design with multiple uncertain parameters using fuzzy sets and genetic algorithm. J Hydrol Eng 10:386-394

Han JC, Huang GH, Zhang H, Zhuge YS, He L (2012) Fuzzy constrained optimization of eco-friendly reservoir operation using self-adaptive genetic algorithm: a case study of a cascade reservoir system in the Yalong River, China. Ecohydrology 5:768-778

He Z, Wen X, Liu H, Du J (2014) A comparative study of the artificial neural network, adaptive neuro-fuzzy inference system and support vector machine for forecasting river flow in the semiarid mountain region. J Hydrol 509:379-386

Hundecha Y, Bardossy A, Theisen HW (2001) Development of a fuzzy logic-based rainfall-runoff model. Hydrol Sci J 46(3):363-376

Icaga Y (2007) Fuzzy evaluation of water quality classification. Ecol Indic 7:710-718

Ip WC, Hu BQ, Wong H, Xia J (2009) Applications of a grey relational method to river environment quality evaluation in China. J Hydrol 379:284-290

Jeong C, Shin JY, Kim T, Heo JH (2012) Monthly precipitation forecasting with a neuro-fuzzy model. Water Resour Manag 26:4467-4483

Jia X, Morel G, Martell-Flore H, Hissel F, Batoz JL (2016) Fuzzy logic based decision support for mass evacuations of cities prone to coastal or river floods. Environ Model Softw 85:1-10

Jiang WG, Li J, Li ZW (2008) Fuzzy assessment of the population risk of the flood disaster. J Hunan Univ [Nat Sci] 35(9):84-87 [in Chinese]

Jiang W, Deng L, Chen L, Wu J, Li J (2009) Risk assessment and validation of flood disaster based on fuzzy mathematics. Prog Nat Sci 19:1419-1425

Keskin ME, Terzi O, Taylan D (2004) Fuzzy logic model approaches to daily pan evaporation estimation in western Turkey. Hydrologic Sci J 49(6):1001-1010

Keskin ME, Terzi Ö, Taylan D (2009) Estimating daily pan evaporation using adaptive neural-based fuzzy inference system. Theor Appl Climatol 98:79-87

Kisi O (2004) Daily suspended sediment modeling using a fuzzy differential evolution approach. Hydrol Sci J 49:183-197

Kisi O, Karahan ME, Şen Z (2006) River suspended sediment modeling using a fuzzy logic approach. Hydrol Process 20:4351-4362

Kojiri T (1988) Real-time reservoir operation with inflow prediction by using fuzzy inference theory In: Seminar on conflict analysis in reservoir management, session F. Asian Institute of Technology, Bangkok, Thailand

Laxmi Mohanta V, Singh S, Kumar Mishra B (2019) Human health risk assessment of fluoride-rich groundwater using fuzzy-analytical process over the conventional technique. Groundw Sustain Dev 10:100291

Liou SM, Lo SL, Hu CY (2003) Application of two-stage fuzzy set theory to river quality evaluation in Taiwan. Water Res 37:1406-1416

Lobbrecht AH, Solomatine DP (1999) Control of water levels in polder areas using neural networks and fuzzy adaptive systems. In: Savic D, Walters G (eds) Water industry systems: modelling and optimization applications. Research Studies Press Ltd., Baldock, pp 509-518

Lohani AK, Goel NK, Bhatia KKS (2007) Deriving stage-dischargesediment concentration relationships using fuzzy logic. Hydrol Sci J 52:793-807

Lohani AK, Goel NK, Bhatia KKS (2014) Improving real-time flood forecasting using fuzzy inference system. J Hydrol 509:25-41

Mamdani EH, Assilion S (1974) An experiment in linguistic synthesis with a fuzzy logic controller. Int J Man Mach Stud 7:1-13 
Mao DH, Wang LH (2002) Diagnosis and an assessment on the vulnerability of the urban flood-waterlogged disaster in the human province. Resour Environ Yangtze Basin 11(1):89-93 [in Chinese]

Minatour Y, Bonakdari H, Zarghami M, Bakhshi MA (2015) Water supply management using an extended group fuzzy decisionmaking method: a case study in north-eastern Iran. Appl Water Sci 5:291-304

Mirbagheri SA, Nourani V, Rajaee T, Alikhani A (2010) Neuro-fuzzy models employing wavelet analysis for suspended sediment concentration prediction in rivers. Hydrol Sci J 55(7):1175-1189

More SB, Deka PC (2017) Estimation of saturated hydraulic conductivity using the fuzzy neural network in a semi-arid basin scale for murum soils of India. ISH J Hydraul Eng 5010:1-7

Muhammetoglu A, Yardimci A (2006) A fuzzy logic approach to assessing groundwater pollution levels below agricultural fields. Environ Monit Assess 118:337-354

Mujumdar P, Ghosh S (2008) Chapter 12: fuzzy logic-based approaches in water resource system modelling. In: Abrahart RJ, See LM, Solomatine DP (eds) Practical hydroinformatics. Water science and technology library, vol 68. Springer, Berlin, pp 165-176

Mujumdar PP, Sasikumar K (2002) A fuzzy risk approach for seasonal water quality management of a river system. Water Resour Res 38:5-9

Nachtnebel HP, Hanish P, Duckstein L (1986) Multicriterion analysis of small hydropower plants under fuzzy objectives. Ann Reg Sci XX:86-100

Nadiri AA, Naderi K, Khatibi R, Gharekhani M (2019) Modelling groundwater level variations by learning from multiple models using fuzzy logic. Hydrol Sci J. https://doi.org/10.1080/02626 667.2018.1554940

Nayak PC, Sudheer KP, Ramasastri KS (2005) Fuzzy computing based rainfall-runoff model for real-time flood forecasting. Hydrol Process 19:55-68

Oroji B, Karimi ZF, Bahrami H (2017) Determine of surface water quality index in Iran. J Environ Earth Sci 7(2):53-63

Oxford University Press (1998) International federation of red cross and red crescent societies. World disaster report. Oxford University Press, Oxford

Ozelkan EC, Duckstein L (2000) Multi-objective fuzzy regression: a general framework. Comput Oper Res 27(7-8):635-652

Özelkan EC, Duckstein L (2001) Fuzzy conceptual rainfall-runoff models. J Hydrol 253:41-68

Özelkan EC, Galambosi Á, Duckstein L, Bárdossy A (1998) A multiobjective fuzzy classification of large scale atmospheric circulation patterns for precipitation modeling. Appl Math Comput 91:127-142

Ozger M (2009) Comparison of fuzzy inference systems for streamflow prediction. Hydrol Sci J 54:261-273

Panigrahi DP, Mujumdar PP (2000) Reservoir operation modelling with fuzzy logic. Water Resour Manag 14:89-109

Parker DJ (2000) Introduction to floods and flood management. Floods, vol 1. Routledge, London, pp 3-39

Partal T, Kişi Ö (2007) Wavelet and neuro-fuzzy conjunction model for precipitation forecasting. J Hydrol 342:199-212

Patel JN, Balve PN (2016) Evapotranspiration estimation with fuzzy logic. Int J Adv Mech Civ Eng 3(4):20-23

Patki VK, Shrihari S, Manu B, Deka PC (2013) Fuzzy system modeling for forecasting water quality index in the municipal distribution system. Urban Water J 12:89-110

Perera EDP, Lahat L (2015) Fuzzy logic based flood forecasting model for the Kelantan River basin, Malaysia. J Hydro Environ Res 9:542-553

Pesti G, Shrestha B, Duckstein L, Bogardi I (1996) A fuzzy rulebased approach to drought assessment. Water Resour Res 32(6):1741-1747
Pramanik N, Panda RK (2009) Application of neural network and adaptive neuro-fuzzy inference systems for river flow prediction. Hydrol Sci J 54:247-260

Quiroz Londoño OM, Romanelli A, Lima ML, Massone HE, Martínez DE (2016) Fuzzy logic-based assessment for mapping potential infiltration areas in low-gradient watersheds. J Environ Manag 176:101-111

Rajaee T (2010) Wavelet and neuro-fuzzy conjunction approach for suspended sediment prediction. CLEAN Soil Air Water 38:275-288

Sahay RR, Sehgal V (2014) Wavelet-ANFIS models for forecasting monsoon flows a case study of the Gandak River (India). Water Resour 41:574-582

Sedeño-Díaz JE, López-López E (2016) Fuzzy logic as a tool for the assessment of water quality for reservoirs: a regional perspective (Lerma River Basin, Mexico). Lake Sci Clim Change 5:155-174

Shrestha BP, Duckstein L, Stakhiv EZ (1996) Fuzzy rule-based modeling of reservoir operation. J Water Resour Plan Manag 122(4):262-269

Simonovic SP (1992) Reservoir systems-analysis - the closing gap between theory and practice. J Water Resour Plan Manag 118(3):262-280

Simonovic SP (2008) Managing water resources : methods and tools for a systems approach, vol 40. Routledge, Abingdon, pp 157-165

Sivapragasam C, Sugendran P, Marimuthu M, Seenivasakan S, Vasudevan G (2008) Fuzzy logic for reservoir operation with reduced rules. Environ Prog 27(1):98-103

Sugeno M, Yasukawa T (1993) A fuzzy logic based approach to qualitative modeling. IEEE Trans Fuzzy Syst 1(1):7-31

Surendra HJ, Deka PC (2014) Development of a fuzzy logic based model using different membership and rules criteria for predicting water consumption using climatic variables, vol 5, pp 1293-1301

Talei A, Chua LHC, Wong TSW (2010) Evaluation of rainfall and discharge inputs used by adaptive network-based fuzzy inference systems (ANFIS) in rainfall-runoff modeling. J Hydrol 391:248-262

Talei A, Chua LHC, Quek C, Jansson PE (2013) Runoff forecasting using a Takagi-Sugeno neuro-fuzzy model with online learning. J Hydrol 488:17-32

Teegavarapu RSV, Simonovic SP (1999) Modeling uncertainty in reservoir loss functions using fuzzy sets. Water Resour Res 35(9):2815-2823

Terzi Ö, Erol Keskin M, Dilek Taylan E (2006) Estimating evaporation using ANFIS. J Irrig Drain Eng 132:503-507

Teutschbein C, Wetterhall F, Seibert J (2011) Evaluation of different downscaling techniques for hydrological climate-change impact studies at the catchment scale. Clim Dyn 37:2087-2105

Theodoridou PG, Varouchakis EA, Karatzas GP (2017) Spatial analysis of groundwater levels using fuzzy logic and geostatistical tools. J Hydrol 555:242-252

Valverde MC, Araujo E, Campos Velho H (2014) Neural network and fuzzy logic statistical downscaling of the atmospheric circulation-type specific weather pattern for rainfall forecasting. Appl Soft Comput J 22:681-694

Varouchakis EA, Theodoridou PG, Karatzas GP (2019) Spatiotemporal geostatistical modeling of groundwater levels under a Bayesian framework using means of physical background. J Hydrol 575:487-498

Venkat Kumar N, Mathew S, Swaminathan G (2009) Fuzzy information processing for assessment of groundwater quality. Int J Soft Comput 4(1):1-9

Vernieuwe H, Georgieva O, De Baets B, Pauwels VRN, Verhoest NEC, De Troch FP (2005) Comparison of data-driven Takagi-Sugeno models of rainfall-discharge dynamics. J Hydrol 302(1-4):173-186

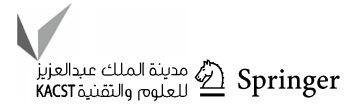


Wang LX, Mendel JM (1992) Generating fuzzy rules by learning from examples. IEEE Trans Syst Man Cybern 22(6):1414-1427

Wieprecht S, Tolossa HG, Yang CT (2013) A neuro-fuzzy-based modeling approach for sediment transport computation. Hydrol Sci J 58:587-599

Young CC, Liu WC, Chung CE (2015) Genetic algorithm and fuzzy neural networks combined with the hydrological modeling system for forecasting watershed runoff discharge. Neural Comput Appl 26:1631-1643
Yu PS, Chen ST (2005) Updating real-time flood forecasting using a fuzzy rule-based model. Hydrol Sci J 50:265-278

Zadeh LA (1965) Fuzzy sets. Int J Inf Control 8:338-353

Publisher's Note Springer Nature remains neutral with regard to jurisdictional claims in published maps and institutional affiliations. 